\title{
24
}

\section{Translating the 18th century pudding}

\author{
Helen Leach \\ Anthropology Department, University of Otago, New Zealand \\ helen.leach@stonebow.otago.ac.nz
}

\section{Introduction}

As Atholl Anderson has showed throughout his career, cross-cultural comparisons can improve our understanding of the origins and subsequent history of Pacific cultures. Comparative material can be sourced from within the Pacific basin, or from as far afield as Scandinavia and northern Europe. In this exercise in historical anthropology, offered in celebration of Atholl's valued contributions to cross-cultural studies, the comparison throws light on a feature of Polynesian and British culinary cultures in the 18th century: the pudding. I will argue that Captain Cook and his scientists' translation of dishes like the Tahitian mahi popoi as 'puddings' was not a trivial categorisation, but one based on a deep understanding of the roles that puddings played both in England and Tahiti.

\section{European experience of Polynesian puddings}

On each of Captain Cook's three voyages to the South Seas, the journals kept by the officers and scientists describe the preparation of special dishes by Polynesian cooks to which the observers commonly gave the name 'pudding'. One of the best accounts of a Tahitian dish of this type was provided by James Cook himself, on September 41777 during the third voyage:

There was also a large pudding which I saw the whole process in making, it was made of Bread fruit, Ripe Plantains, Taro and Palm or Pandanes [pandanus] nuts, each rasped, scraped or beat up fine, and baked by it self, a quant[it]y of Juice express'd from Cocoa nut Kernels was put into a large tr[a]y or wooden Vessel, amongst it the other Articles pipeing hot as they were taken out of the Oven and a few hot stones just to keep the whole semmering; three or four men kept stiring the whole with sticks, till the several articles were incorporated one with a nother and the juice of the Cocoanut was turned to oil; so that the whole was about the consistency of hasty pudding (Beaglehole 1967:206-207).

Cook's description is valuable for the detail of both the ingredients and the process of preparation. He and some of his officers and scientists had previous experience with these dishes on which to draw. Soon after the Endeavour arrived at Tahiti on the first voyage, Sydney Parkinson saw several composite dishes being made. He recorded a dish made from starch extracted from the Polynesian arrowroot, mixed with coconut 'liquor', and thickened with hot 
stones 'till it formed a strong jelly: on tasting it we found it had an agreeable flavour, not unlike very good blanc-mange' (Parkinson 1972:17). Though he didn't equate this arrowroot dish with a pudding, he saw other dishes that were comparable:

These people make up various kinds of paste, one of which, called Makey [mahi] Poe Poe [popoi], is made of fermented bread-fruit, and a substance called Meiya [meia - a type of banana], mixt with cocoa-nut milk, and baked, tastes very sweet. In making these pastes, they use a pestle made of a hard black stone, a kind of basaltes, with which they beat them in a wooden trough (Parkinson 1972:17; cf. Lepofsky 1994:79, 94).

As one of the expedition artists, Parkinson supplied an illustration and description of this heavy stone pestle (Parkinson 1972:76). For Parkinson, the terms paste and pudding overlapped in meaning, as is apparent in his vocabulary listing for Poe, as 'A paste, or pudding, made of the roots of arum [taro]' (Parkinson 1972:75).

On the second voyage, again in Tahiti, George Forster recorded on April 231774 that his father had eaten 'a rich and most delicious kind of pudding, which is made of the kernel of coconuts and eddy-roots [taro], scraped very small, and mixed together' (Forster 2000:352). Tahiti was just one of several Polynesian islands where Cook's men encountered puddings. On July 11 1777 William Anderson summed up Tongan cookery with the following telling remark:

They are as yet almost strangers to the thousand destructive luxurys which cookery has invented, but nevertheless have a few artificial dishes, such as a soft pudding made of Talo and other roots with Cocoa nut scrap'd into it, which gives an agreeable smoothness to every thing dress'd with it (Beaglehole 1967:942).

As missionaries and traders settled the other island groups inhabited by Polynesians, they found similar dishes, which differed from the usual chunks of baked fruit and vegetables that formed the daily diet of commoners. The distinguishing features were the amount of labour invested in achieving the paste-like consistency and the frequent addition of coconut cream. These dishes were served at feasts and notably to chiefs and important visitors. They were associated with valuable artefacts such as dressed basalt or calcite pounders, and large wooden vessels. As a component of feasts, puddings would also have been eaten by commoners, though such dishes were not made from the highest-ranked fruits or root crops (Leach 2003). It might be expected that on islands where society was less stratified than on Tahiti or Hawai'i, and fewer foods were proscribed for commoners, puddings marked feasts rather than the differential status of consumers. Nevertheless the inter-island similarities were such that it was not simply an English category name that grouped puddings together, but a Polynesian food concept that was clearly of some antiquity.

\section{The elements and antiquity of Polynesian puddings}

The appearance of what were obviously related dishes throughout West and East Polynesia stimulated To'aiga Su'a to investigate the history of this category in her Master's thesis in Anthropology (Su'a 1987). She assembled data on a large number of named dishes of this type and established that each had certain features in common:

- one (occasionally more) starchy foundation ingredient, either root crops such as yams, taro, or sweet potato, or fruit such as breadfruit or bananas;

- a softening, lubricating ingredient, usually coconut cream; 
- a homogeneous texture achieved through the application of a consistent set of techniques, such as pounding, mashing, kneading, grating, and stirring.

In West Polynesian island groups, grating was a common technique for preparing the starchy base from a raw state. In East Polynesia, pounding was more prevalent. Where the base was pre-cooked, pounding was commonly practised, though it was not necessary to use a heavy stone pestle. If the pudding was made from a fermented starch paste, kneading might suffice. The desirable qualities of the pudding were its power to satiate the eater, the richness of flavour and aroma usually imparted by the coconut cream, and the smooth oily texture and correct viscosity for the particular dish (Su'a 1987:255-256).

There is no generic term for these dishes in Polynesia. They sometimes appear as binomials, combining the name of the foundation or emollient ingredient and the preparation technique. Among the range of names are some that have cognates in several island groups. These include fakakai (also fai'ai, feikai and fekei), loloi (also roroi), poke (po'e), (po)poi, (su)sua, tukituki, taufolo, and vaihalo (Leach 1989:133-134). Some of these terms relate to processing, such as poke, to mix, and tuki, to pound, while others refer to processing tools like graters. Others refer to preserved starch crop pastes, such as poi, that could also become the foundation of a dish. Based on the widespread use of these words, historical linguists have reconstructed many of them for the Proto-Polynesian language spoken up to three millennia ago and to Proto-Nuclear Polynesian in use in Western Polynesia 2000 years ago (Su'a 1987:193-209). For example, the Proto-Polynesian reconstruction *fai-kai is glossed as 'food cooked with coconut cream' and PPN *lolo-qi is glossed as 'to prepare food with coconut cream' (Kirch and Green 2001:158). Since ample archaeological evidence exists for the tools themselves, especially the heavy stone or calcite pounders, stone grating heads, and perforated shell peelers, we can confidently state that this category of dish was present in Pacific Island societies at the time that Polynesians separated into their major Western and Eastern divisions, and may even have been present when the Polynesians split from other Oceanic speakers of Austronesian languages.

Anthropologists are uniquely placed to conduct cross-cultural investigations. In the case of the smooth-paste pudding dishes seen in the Pacific, To'aiga Su'a (1987) examined their history, distribution, material culture, nomenclature, and social significance right through to the 20th century. But her study was focused on Polynesian cultures. There were people of other cultures present when the 18th century descriptions were made, and in choosing to call these dishes puddings, and specifically hasty puddings, they were making a cross-cultural comparison. The English officers and scientists were pudding eaters themselves. This paper will now examine the English pudding traditions that inspired the identification of these Polynesian dishes as puddings, and one in particular as a hasty pudding. But we cannot assume that what we mean by 'pudding' in the 21st century applied to the 18th century pudding. The English pudding of our ancestors needs almost as much effort in translation as that of the exotic cultures of Polynesia.

\section{The English and North American 'hasty pudding'}

What similarities did Cook have in mind in likening the Tahitian pudding to a hasty pudding? This question is best answered from the study of actual recipes. The earliest recipes for hasty puddings appear in the 17th century. In the revised 1665 edition of Robert May's The Accomplisht Cook, first published in 1660, there are three examples of hasty puddings. The first reveals by the wording of its title the origin of this pudding name - 'To make a Pudding in haste' (May 
2000:179). The recipe calls for a pint of milk or cream, a handful each of raisins and currants, and a piece of butter. A handful of flour is stirred into it. The milk is brought to the boil, and bread and nutmeg grated in. After a quarter of an hour's boiling, it is dished up on beaten butter. The instructions are somewhat out of order and fail to note the problems of leaving a pot of thickened milk to boil. The second recipe is unlike most hasty puddings in that the flourthickened cream is transferred to a floured cloth and boiled. The third recipe is more explicit and better arranged: two or three pints of thick cream are brought to the boil in a skillet. Then grated bread, flour, nutmeg, sugar and butter are added. The cook is instructed to 'stir them continual' (May 2000:181). Halfway through the cooking process the yolks of six eggs are stirred in. The finished hasty pudding is poured into a dish, decorated with thinly sliced candied orange peel, and enriched with some beaten butter and scrapings of loaf sugar.

Two of May's three recipes show features that were to characterise the 18th century hasty pudding:

- they were cooked quickly in a pot or pan, unlike other pudding types that were either boiled in a gut casing, cloth or wooden bowl for several hours, or baked in the oven for three-quarters of an hour, or longer;

- they were stirred continuously - though the rationale was not stated, this was to prevent the mixture burning on the bottom of the pot or forming lumps.

Many recipes have a long life in English cookery books, often of several centuries (for longsurviving soups see Leach 2006); however, as an increasingly popular style of dish, pudding types developed and diversified quite quickly over the 18th and 19th centuries. To determine what sorts of hasty puddings Captain Cook would have been familiar with, a century after Robert May's book appeared, we need to consult the popular recipe books used in 18th century kitchens. Apart from Sir Joseph Banks, it is unlikely that Cook's officers and scientists regularly dined in elite households; so we must choose cookbooks that contained dishes they would have known since childhood. In the first half of the 18th century, English recipe books fall into two groups: those presenting a fashionable cuisine strongly influenced by the French court, and those reproducing English cookery for middle-class households. Most of the former works were authored by male chefs, while the latter were predominantly compiled by women (Lehmann 1999a:277-279). Since the French had no dishes in their repertoire at that time that matched the English pudding, we can turn to female writers such as Eliza Smith (1734) and Hannah Glasse (1995 [1747]) for widely known examples of 18th century hasty puddings.

The first recipe for 'Hasty-Pudding' in Eliza Smith's The Compleat Housewife involved a different method of incorporating the flour into the boiling milk from that in the 17 th century recipes. The flour was first mixed with an egg, then formed into a very stiff paste that was shredded into the milk, a bit like pasta, along with cinnamon, sugar and a knob of butter. Smith (1734:96) advised cooks to 'Keep it stirring all one way, till 'tis as thick as you would have it; and then stir in such another piece of Butter'. Her second recipe was for 'little Hasty-puddings' that started by boiling milk and flour 'into a smooth Hasty-pudding' (Smith 1734:105). The thickened mixture was sweetened, flavoured with nutmeg, and left to cool. Beaten eggs were then stirred into it and the mixture poured into custard cups, which were covered and boiled for more than half an hour. This recipe starts as a hasty pudding but is then processed as individual baked custards.

In 1747, Hannah Glasse offered three versions of hasty pudding: one thickened with wheat flour, one with oatmeal, and the third with the flour and egg paste employed in Eliza Smith's second recipe. In fact, the wording strongly suggests that it was copied directly from Smith. In 
the first recipe, egg yolks were mixed with cold milk, then hot milk infused with bay leaves was poured over them. The recipe continued with the instruction:

then with a wooden Spoon in one Hand, and the Flower [sic] in the other, stir it in till it is of a good Thickness, but not too thick. Let it boil, and keep it stirring, then pour it into a Dish, and stick Pieces of butter here and there (Glasse 1995:80).

She noted that the eggs were optional, but in her opinion, an improvement.

Glasse's 'Oatmeal Hasty-Pudding' was a plainer dish. Water was brought to the boil, with a piece of butter and some salt added. Then Scotch oatmeal was stirred in progressively. When the mixture was thick, it was poured into the serving dish and dotted with butter. It could also be dressed with ale or wine and sugar, or with cream or new milk (Glasse 1995:80). A similarly plain hasty pudding was published by William Ellis in 1750, in a work addressed to country housewives. This 'common Farmers Hasty-pudding' combined milk (or milk diluted with water) and flour, stirred for quarter of an hour over the fire. Before serving, it too was enriched with butter and/or sugar (Ellis 1750:34).

From these and other examples, we can describe a generic hasty pudding from the mid18 th century as a liquid, usually milk, thickened with one or two starchy cereal products, usually wheat flour, and sometimes dressed before serving with a fat product such as butter or cream. Because it was not normally cooked in an oven or boiled in a cloth or bowl where the heat surrounds the mixture and cooks it evenly, special instructions were included in many hastypudding recipes: the mixture should be stirred continuously as it thickened. This prevented scorching and lumpiness.

When Captain Cook likened the Tahitian dish to a hasty pudding, he was probably aware they both shared a starchy base, a liquid ingredient, and the necessity for continuous stirring as the mixture thickened. He might also have drawn parallels between the oily coconut cream of the Polynesian pudding and the addition of butter to the hasty pudding. Before moving on to consider the wider constellation of 18th century puddings, it is interesting to note the later history of hasty puddings. In Britain, they made fewer appearances in 19th century cookbooks and were absent entirely from some of the most popular works, such as those by Isabella Beeton. Only the most extensive compilations, for example Cassell's Dictionary of Cookery (Anon c. 1875), offered more than a solitary recipe for hasty pudding. A few examples occurred early in the 20th century, but mainly in works recycling 19th century recipes, such as Cassell's Shilling Cookery (Payne 1916:268).

The situation was rather different in North America. Wheat-flour hasty puddings were essentially reproductions or modifications of British examples, while those based on maize meal look like a North American innovation. As an example of a modified hasty pudding, Eliza Leslie's 'Flour Hasty Pudding' (Leslie 1840:301), first published in 1837, replaced the bay leaves used by Hannah Glasse in her first recipe with peach leaves. Since bay laurel leaves were often confused with the true bay in English cookbooks, this substitution may have contributed the same desirable bitter-almond flavour just as readily as bay laurel. The stirring instructions closely follow Glasse's wording and appear to be an edited copy. Though wheat-flour hasty puddings are derivative, those utilising maize cornflour were distinctively American. In their simplest form, they involved stirring the cornmeal into boiling salted water then cooking it till very thick, as in Esther Howland's 'Indian Hasty Pudding' (Howland 1845:40), Catharine Beecher's 'Mush or Hasty Pudding' (Beecher 1850:108), and Elizabeth Lea's 'New England Hasty Pudding, or Stirabout' (Lea 1869:82). There is a suggestion in Lea's recipe that a special stirring stick developed for this dish, for she wrote 'stir well with a wooden stick kept for the purpose' (Lea 1869:82), 
while Fanny Gillette, author of the White House Cook Book, referred to a 'pudding-stick'. Her 'Corn-Meal Mush or Hasty Pudding' was thick enough to serve when the stick stood upright in the mixture (Gillette 1887:243). The name became rare in 20th century American cookbooks, being replaced by Indian Pudding, a modified recipe in which the cornmeal hasty pudding was prepared in a double boiler, then finished off by baking in an oven (Perkins 1949:551-552). It seems likely that an early adaptation of the 17th century English hasty pudding to the new cereal, maize, proved so acceptable in America that it flourished there while the English hasty pudding was losing ground. The pudding stick is thought to have been a stout piece of wood with a paddle-like end.

It is important to remember that before 18 th century Polynesian puddings were likened to hasty puddings, they were categorised by the English observers as puddings in a more generic sense. The range of dishes called puddings in 18th century England included some, such as black puddings, that bore little resemblance to a stone-boiled coconut-cream concoction. However, there were others included in the recipe books that show significant similarities, not just in method or combination of food groups, but in social significance. Recipe books are not the only source of information on pudding characteristics, and indeed they are often silent on the context in which dishes were served or the sorts of people who might have been expected to eat them. Personal diaries and essays provide essential information, especially on the frequency of use of particular dishes and their place in the menu.

\section{Parson Woodforde's puddings, 1767-1802}

For the purpose of this study, the diaries of country parson (and gourmand), the Reverend James Woodforde of Weston Longville, Norfolk, provided important contextual detail. Woodforde was a farmer as well as a parson, and he also maintained an extensive orchard and kitchen garden. In consequence, there was much processing of primary produce, both animal and vegetable, by members of his household. From 1767, there are references in his diaries to puddings, as well as to the meat, fish, poultry and game dishes that provided the core of each of the two courses that constituted 18th century dinners. These entries increased as he settled in to life at Weston Parsonage in 1774-1775. From May 11791 he noted daily the chief dishes served at each dinner when at home or dining locally. Using John Beresford's selections from Woodforde's diaries, I tabulated 282 references to puddings over the period 1788-1802 (Beresford 1927, 1929, 1931). Although 57 simply referred to a pudding, or baked or boiled pudding, or plain or rich pudding, 225 entries specified the type of pudding eaten, sometimes with details of the course in which it was served (Table 1).

Plum puddings were by far the most common and the most prestigious, being served on formal occasions such as the day set aside for the tithe audit, in late November or early December, when the parson provided dinner for his tenant farmers, and on Christmas Day when the puddings were usually accompanied by mince pies. But they were not limited to such events: in 1792, for example, the household ate a baked plum pudding on May 2, and a boiled plum pudding on July 13; unspecified plum puddings were served on October 30 and November 4. Woodforde complained of the insufficient quantity of plum pudding when he ate at the King's Arms on May 18, but not when he dined there again on October 19. Four diary entries indicate that the plum puddings were served with the first course (April 17 1787; May 20 1791; July 13 1792; May 8 1797).

Of all the 18th century puddings, recipes for plum puddings are surprisingly rare. This cannot be because they were made infrequently. Since cooks were required to produce them on a regular basis, they may have known the recipe by heart. Mary Kettilby's (1714:89) 'An 
Table 1. Number of entries for specific dishes called puddings in Parson Woodforde's diaries 1788-1802.

\begin{tabular}{lc}
\hline Dried fruit, e.g.' plum', raisin & 92 \\
Fresh or preserved fruit, e.g. apple, apricot, gooseberry, plum, orange & 42 \\
Suet & 28 \\
Batter, including Norfolk, Yorkshire & 26 \\
Meat, game & 10 \\
Pease & 10 \\
Rice & 9 \\
Black & 3 \\
Custard & 2 \\
Potato & 1 \\
Bread & 1 \\
[Stuffing] in fish & 1 \\
\hline
\end{tabular}

excellent Plumb-Pudding' represents the plum pudding in its modest form: a pound of suet, finely shredded, a pound of stoned raisins, and four spoonfuls each of flour and sugar were mixed together. The yolks of five eggs and whites of three, beaten with a little salt, were then added. The mixture was tied tightly in a [floured] cloth and boiled for at least four hours. Hannah Glasse's 'A boiled Plumb Pudding' of 1747 had the same quantity of suet and raisins as Kettilby's, but had an extra pound of currants, more flour, grated breadcrumbs, three more eggs, a pint of milk, and a quantity of spice (nutmeg and ginger). It was boiled for five hours (Glasse 1995:69). Brandy was a common addition to this richer sort of plum pudding.

The puddings made from fresh or home-preserved fruit recorded in Woodforde's diaries were dominated by damson plums, apples and gooseberries. The damson puddings were eaten in September and October, when the fruit was freshly harvested, as well as in January and March, when it must have been preserved in some form. Hannah Glasse provided one recipe for preserving damsons whole within a damson jelly, and another for preserving them in a syrup with a paper cover and an oil layer to exclude air (Glasse 1995:154, 157). She supplied a recipe for a quince, apricot or white pear plum pudding that may have served as a template: the fruit was pre-cooked and then baked in a dish with a custard of cream and egg yolks (Glasse 1995:107). Alternatively, the damsons may have been cooked within a suet crust, tied in a cloth and boiled, a common method of making apple puddings. After describing this type of apple pudding, Glasse (1995:112) commented 'And thus you may make a Damson Pudding, or any sort of Plumbs, Apricots, Cherries, or Mulberries, and [these] are very fine'. Such fruit-pudding recipes increased in frequency during the second half of the 18th century and flourished in the 19 th when the suet crust was especially common.

As for the gooseberry pudding, Elizabeth Raffald provided a recipe in which cooked gooseberry purée was beaten with sugar, butter, biscuit crumbs and eggs, and then baked for half an hour (Raffald 1970:182). Very similar recipes were published by Elizabeth Moxon (1769:84), Lydia Fisher (1788:37) and Edinburgh cookery teacher Mrs Frazer (1791:116-117). Parson Woodforde ate his gooseberry puddings between the third week in May and mid-July, so we can assume they were made from freshly picked fruit. However, we know that his neighbours, the Custances, preserved gooseberries, for they gave the parson a 'common Quart Bottle of preserved Gooseberries' on October 61792 (Beresford 1927:376). The damson pudding consumed on 
March 71797 appears to have accompanied roast duck in the second course of dinner, but the parson did not provide information as to the course position of his other fruit puddings.

Parson Woodforde recorded another fruit-based pudding in his diaries during the 1770s, which on December 25 1773, was eaten with the first course. This was an orange pudding, which was so popular in the mid-18th century that Hannah Glasse (1995:105-106) provided four different recipes for it. Three of them required 16 egg yolks, and the fourth six. All beat the eggs with from half to one pound of butter, and from half to three-quarters of a pound of sugar. Cream was added in two of the recipes, along with grated Naples biscuits for extra body. The orange flavour was imparted by grating or pounding the rind of one to three Seville oranges. In two cases, the oranges were boiled in several changes of water to eliminate the characteristic bitterness, then pounded in a mortar before being added to the mixture. All four recipes instructed the cook to bake the pudding in a dish lined with puff pastry. These puddings were rich enough to justify inclusion at Christmas dinner. The one lemon pudding referred to on September 271796 may have been prepared in similar fashion.

Suet puddings were on the parsonage menu throughout the year, though a little more often over the colder months. They seem to have been viewed as a suitable accompaniment to boiled beef (May 20 1800; June 30 1802), roast beef (May 11 1796), as well as hashed mutton (August 30 1800), so they probably formed part of the first course. Hannah Glasse's recipe for 'A boiled Sewet Pudding' was a thick batter pudding made from eggs, flour and milk, with the suet adding a richness that is absent from the plain batter pudding. In keeping with its role as a savoury pudding, it was flavoured with ginger and pepper (Glasse 1995:69). Glasse's second suet pudding was placed in a chapter of her book addressed to sea captains. It is more like a basic plum pudding, containing dried fruit (currants and raisins), flour, and ginger, as well as the suet. But instead of eggs, it was mixed with salt water (Glasse 1995:124). Although this recipe offered the option of boiling or baking, most suet puddings were boiled in a well-buttered cloth.

In Woodforde's usage, batter puddings were either plain or sweet. Included in the plain type was Yorkshire pudding, which he invariably ate with roast beef during the first course of dinner (e.g. April 8 1783; July 19 1790; March 14 1797; September 4 1797). It is difficult to know whether by plain pudding, plain batter pudding and Norfolk plain batter pudding, he meant one and the same dish. These puddings were sometimes mentioned in association with roasted meat during the first course, and there is a diary entry for a batter pudding in the first course on June 181781 . By contrast, one of several recorded 'sweet batter puddings' was served in the second course (April 8 1796), accompanied by red-currant jelly. As with plum puddings, batterpudding recipes were so well known they were often omitted from recipe books. However in 1747, Hannah Glasse provided two, one with eggs and one without. The cook was instructed to mix six spoonfuls of flour with a little milk, some salt and ginger, then to add the rest of the quart of milk, six egg yolks and three whites. The batter was to be boiled for one and a quarter hours, and served with melted butter. In the eggless version, tincture of saffron was added (to compensate for the absence of bright yolks), and it was boiled for just one hour; dried fruit could be added if desired (Glasse 1995:108). But no instructions were supplied for preparing these puddings for cooking. Fortunately, Lydia Fisher (1788:36) was more explicit: 'you must take care your pudding is not thick; flour your cloth well. Three quarters of an hour will boil it.'

References to meat and game puddings included beef-steak, rabbit, pigeon, blackbird and sparrow puddings. The steak pudding was a clear predecessor of the steak and kidney pudding that appeared in the second half of the 19th century (Beeton 1869:288). The meat was seasoned and enclosed in a suet crust pastry. This was tied in a cloth and boiled for three to five hours 
depending on size. Hannah Glasse's 1747 recipe gives the impression that the development of this relatively new type of pudding was linked to the practice of cooking apple slices in a suet crust: 'make it up as you do an Apple-pudding ... This is the best Crust for a Apple-pudding. Pigeons eat well this Way' (Glasse 1995:69).

William Ellis (1750:37) described a similar type (made with lard instead of suet) as 'Applepudding, the Hertfordshire Way' and implied that it was more economical than the cream and egg-yolk variety. In the absence of specific recipes for rabbit and small-bird puddings, we can only assume that they too were boiled within some sort of crust.

Pease pudding was a standard accompaniment to pork, and at Weston Parsonage, it was always served with a boiled leg of pork. On one occasion, James Woodforde suspected that it had made him ill (February 28 1782), but he continued to eat it with boiled pork till at least 1798. This simple pudding of dried split peas boiled in a cloth is often thought to be of medieval origin (Kelsey 1995:117); however the Oxford English Dictionary provides no examples of usage before the 18th century and no earlier recipes have been located. In contrast, pease pottage (an early form of soup) was common in the Middle Ages, and was cooked in a pot over the fire. The 18 th century recipes for pease pudding recommended that split peas be boiled, loosely tied in a cloth, for one hour, then mixed with butter and seasoning, retied, and boiled for a further hour before serving (e.g. Frazer 1791:111).

In contrast, rice puddings were already of considerable antiquity by the 18th century, and so many recipes were in circulation that it is hard to know which ones were familiar to Woodforde and his household. He ate rice puddings both baked (e.g. June 30 1789; October 7 1794) and boiled (e.g. April 28 1790). He noted that on March 29 1792, the rice pudding formed part of the second course, while on April 20 1796, it was part of the first course. A century earlier, when Robert May's cookbook was in print, rice puddings were baked, boiled in cloths, or stuffed into the small intestines of pigs or sheep - probably the earliest form in which they were made (e.g. Murrell 1615). The rice was generally pre-boiled in milk or cream, then mixed with eggs, suet or bone marrow, grated bread, dried fruit, sugar, and flavourings such as rosewater, cinnamon, nutmeg or coriander (May 2000:21, 182). In 1747, Hannah Glasse (1995:108, 111, 124) gave recipes for nine different rice puddings. In these, the suet and marrow commonly used in the 17 th century had been replaced by butter, and in the case of the baked rice puddings, milk was more common than cream for pre-boiling the rice. The simplest and cheapest rice puddings were composed of rice boiled in a cloth with or without some raisins, then dressed with melted butter before serving. By the 19th century, the suite of flavourings used in rice puddings had moved from nutmeg, mace and cinnamon to lemon and vanilla, and the majority were much less rich than their 17 th century counterparts.

Potato puddings were a popular 18th century dish that lost ground during the 19th century. All began with pre-cooked mashed potatoes and butter. Other ingredients were added according to the richness desired: beaten eggs, sugar, cream, sack or brandy, currants, candied peel, or orange juice. The thick mixture could be boiled in a cloth, baked in a buttered dish, or poured into a pie dish lined with puff pastry (Glasse 1995:98, 105). On one occasion, James Woodforde ate 'a Rice and Potatoe Pudding' (October 4 1784), but potato puddings were infrequently served at the parsonage.

Two other pudding categories figured in Woodforde's diaries and these reflect the survival of the earliest forms of pudding from the late-medieval and early-modern period: puddings as stuffing for cavities in roasted birds, fish and larger animals (Austin 1888:41-42, 61), and puddings as stuffed intestines or paunches, or wrapped in membranes known as caul. The former lost the name 'pudding' towards the close of the 18th century, and became 'forcemeat' or 
'farcing', and more recently 'stuffing'. The latter survive as the type of sausage we still call black and white puddings. The etymology of the word pudding has been subject to some debate, in particular as to whether the Middle English term poding shares the same root as 14th century Old French bodeyn, bowel (OED 2006-7). The antiquity of pudding recipes involving stuffing of gut portions supports the theory that the term was extended from the gut to the stuffing, and then to the stuffing by itself. Karen Hess summed up the subsequent evolution of the word and its glosses in 1981:

... English puddings early on became ever more farinaceous, more porridgy, than their French counterparts, where such practice is regarded as adulteration. Most fifteenth-century pudding recipes already call for bread crumbs or ote-mele, and eventually, the pudding-bag became a surrogate maw or intestine for boiling the gutless - and meatless - sweet pudding (Hess 1981:102).

The process took several centuries, judging from the number of recipes in Robert May's 1685 cookbook for sweet puddings forced into lengths of gut. But 100 years later, the only sausage-like puddings made in Parson Woodforde's household were black puddings, prepared from a Somerset recipe obtained in 1786. This activity followed the annual killing of one of the household's own pigs in November or December. During the 19th century, recipes for black (blood) puddings were omitted from cookbooks addressed to urban housewives, as they no longer ate home-killed pork. They survived in Scottish recipe books into the 20th century (e.g. Guthrie Wright 1911:93).

Woodforde probably grew up hearing the stuffing in carcasses referred to as 'puddings'. For the majority of his diary entries he used this term. For example, he ate a pike 'rosted for dinner with a Pudding in his Belly' on June 4 1777, and again on March 6 1797. A 'Fowl rosted with a Pudding in its Breast' was part of the second course on May 8 1797. However, the modern term was already spreading and a 'fine Leveret rosted with stuffing in his Belly' was on the Parsonage menu on September 1, 1801, and 'a large Fowl ... boiled ... with Stuffing in his Breast' on November 171798 (Beresford 1931:17, 34, 147, 335).

Combining the details of pudding consumption from the long span of James Woodforde's diaries with the range of pudding recipes available from several of the most popular 18th century cookbooks has provided a picture of the types of puddings likely to have been familiar to members of Cook's expeditions. From this, we can single out several that shared the smoothness and richness of the Polynesian pudding: hasty puddings, batter puddings, pease puddings, and some of the sweet puddings where the starchy foundation ingredient was reduced to a paste, as in rice flour and potato puddings. In each case, extensive stirring, beating or mashing was required, just as in the South Seas puddings. The application of the term 'pudding' to the 18th century Polynesian dishes was both appropriate and instructive.

\section{The iconic status of 18th century puddings}

One more comparison needs to be made beyond the level of specific recipes and daily menus. We know that Polynesian puddings were served to chiefs and important guests, and that the dish was of such social and ceremonial significance that it had been an integral part of Polynesian feasts for several millennia. Did English puddings hold the same position? They did not have the same antiquity, at least not with the name 'pudding', but a case can be put that by the 18th century, puddings had achieved iconic status. This does not mean that all types of pudding were equally esteemed. Becoming an icon has more to do with symbolism and identity than with rank or status. An early clue that this was underway can be found in a change in the gloss for pudding between the third and fourth editions of Nathan Bailey's An Universal Etymological 
English Dictionary. In the earlier (1726), a pudding was 'a Dish of Food well known; also Hog'sPuddings, \&', while in the next (1728) and some later editions (e.g. the eighth of 1737), the entry read 'a sort of Food well known, chiefly in England, [such] as Hog's Puddings, \&'. Can we identify a particular cause for this amendment? A few years before 1728, a paradoxical encomium had appeared, the work of either Henry Carey or Dr John Arbuthnot (Miller 1956:169fn), entitled A Learned Dissertation On Dumpling; its dignity, antiquity, and excellence. With a word upon pudding... (Carey 1726; Arbuthnot 1751). The encomium argued that flour and water dumplings evolved into puddings with the substitution of milk for water and the addition of marrow, butter, sugar and 'plumbs' (i.e. dried fruit). When eggs were introduced, 'the Pudding became a Pudding of Puddings' and 'From that Time the English became so famous for Puddings, that they are call'd Pudding-Eaters all over the World, to this Day' (Arbuthnot 1751:59). After demonstrating that virtually every food was a form of pudding, as well as many other things from bag-pipes to the human head, poetry, and kingdoms, and that even the universe is but a pudding of elements, the author concluded 'Let not Englishmen therefore be ashamed of the Name of Pudding-Eaters; but, on the contrary, let it be their Glory' (Arbuthnot 1751:70-71). Dr Arbuthnot may not have been the author of this encomium; however its resonance with his greatest literary character, the archetypal Englishman John Bull, is striking.

John Bull quickly became an icon of robust Englishness, along with the pudding. William Ellis introduced a pudding recipe in his 1750 book with the following affirmation of its national importance:

Pudding is so necessary a part of an Englishman's food, that it and beef are accounted the victuals they most love. Pudding is so natural to our harvest-men, that without it they think they cannot make an agreeable dinner (Ellis 1750:33).

Another famous Englishman, Dr Johnson, may have been influenced by the Dissertation On Dumpling. On his tour with Boswell to the Hebrides, Johnson was so scornful of the Reverend James Hervey's Meditations and Contemplations that he created a parody, entitled 'Meditation on a Pudding', which also linked the ingredients of a pudding to universal themes (Chapman 1930:397-398). Whether Dr Johnson felt patriotic when presented with a steaming plum pudding is unclear.

The nationalistic associations of the English pudding need to be seen in their political context. As Gilly Lehmann (1999b:72-73, 75) has shown, from the late 17th century, French cooks were brought in to cook for the Whig elite, prompting a reaction by the Tory gentry which dismissed French dishes as ostentatious, disguised and expensive. Tories ate solid English fare epitomised by roast beef and pudding. Lehmann (1999b:80) quotes James Woodforde's condemnation of a meal he took at a grand house in August 1783, where 'most of the things [were] spoiled by being so frenchified in dressing'. In food at least, Woodforde's repertoire of puddings placed him as a Tory as well as an Englishman.

The iconic status of the pudding continued into the 19th century but seems to have become more focused, in particular on the plum pudding. William Kitchiner, author of The Cook's Oracle, emphasised that 'A little brandy... is an improvement to this excellent British Pudding, which is truly a British dish, [along] with roasted sirloin of beef...' (Kitchiner 1817:553). However, some writers began to adopt a less enthusiastic attitude, in parallel with the prints of the caricaturist James Gillray who from the 1790s began to depict John Bull as 'grotesquely ugly, moronic, [and] gullible' (Rogers 2003:163). Christian Johnstone, writing as Meg Dods on the subject of fruit puddings or charlottes, observed that the French did not esteem 'the solid, lumpy, and doughy English pudding...' (Johnstone 1826:282). The anonymous 'Lady' author of Domestic 
Economy (Anon 1827) justified the omission of a 'great many puddings' in order to 'give room to other matter which appeared of more consequence, as pudding is a real national dish, and better understood than most other dishes' (Anon 1827:552fn). By the time Isabella Beeton was writing, the criticism of the English masses for their taste in puddings was less muted:

Here [in Great Britain], from the simple suet-dumpling up to the most complicated Christmas production, the grand feature of substantiality is primarily attended to. Variety in the ingredients, we think, is held only of secondary consideration with the great body of the people, provided that the whole is agreeable and of sufficient abundance (Beeton 1869:620).

For the Polynesian pudding-eaters, substantiality was also a desirable quality of the pudding, and its power to create a feeling of satiation was specifically mentioned by informants (Su'a 1987:251).

What is clear is that during the 18th century, Englishmen saw the pudding as their national icon, a culinary offering for John Bull. They would not have shared its symbolic meaning lightly with non-English peoples. When they applied the word 'pudding' to Polynesian dishes, it was not just on the grounds of parallels in composition and method. They must have been conscious that in the South Seas these 'puddings' were more than a laboriously prepared dish, with a starch base and enriching 'cream'. Polynesian puddings epitomised the best of Polynesian culinary culture in all of the island groups they visited. The translation as 'puddings' of what they saw in preparation, and ate as honoured guests, reflected an impressive level of crosscultural understanding.

\section{Postscript: Puddings after the 18th century}

The 19th century saw major changes in kitchen technology, in particular the spread of castiron ranges, and then gas stoves. New ingredients appeared, such as chemical raising agents, coconut and bananas. The number of pudding recipes exploded, with many given the names of important towns, or eminent people. The trend away from cooking puddings in gut casings that had been obvious through the 18th century, was now complete, and during the 19th century a similar shift affected puddings encased in cloths. The pudding cloth had been appropriate when mixtures such as pease or plain-batter puddings were cooked in large boilers at the same time as joints of meat. However, for the most delicate puddings, the rolling action of the boiling water was detrimental to their final appearance. Students at the National School of Cookery in 1876 were told that boiled puddings 'are lighter if boiled in a cloth, but easier to keep in shape if boiled in a basin' (Tegetmeier 1876:120). Manufacturers responded to this trend by patenting special pudding basins, including some that did away with the cloth tied over the top of the bowl. Judging from the frequent warnings about the importance of using a truly clean cloth, untainted by the flavour of soap, the task of maintaining the cloth in good condition after it was repeatedly floured or smothered in butter was onerous. The students were told 'It is most essential to keep a pudding cloth clean; it should be washed in two or three hot waters without soap immediately it is done with, wrung dry, and dried off quickly, or it will get a musty taste' (Tegetmeier 1876:120).

A new type of cooking method was adopted towards the end of the 19th century: steaming. This term was applied to two techniques. In the first, the pudding was cooked in a basin standing on a saucer within a pot, with the boiling water half way up the side; in the second, the pudding basin was placed on a rack above the boiling water or in the top half of a double saucepan. Though steamed puddings took longer to cook, their contents were protected from knocks, and if an inner paper cover was used, the cloth did not have to be floured or buttered. A smaller 
saucepan could be used, taking up less room on the stove top than a big iron boiler. Less boiling water was required, hence less fuel. However the risk of the pot boiling dry was acknowledged. Cooks were instructed to ensure that the level was maintained by additions from the boiling kettle. Steaming was the most suitable method of cooking a pudding on the top of a gas stove, where the burners delivered heat to small, circular areas.

In the first half of the 20th century, steaming and baking were the most popular methods of cooking hot puddings in New Zealand. In a study of the cooking methods applied to 885 dishes called puddings in a time series of 17 recipe books, the frequency of puddings cooked by steaming reached 50 percent in 1915 , while those that were boiled in a cloth varied from a maximum of 15 percent in 1926 down to 2 percent in 1955 . The only type of pudding boiled in a cloth from the 1950s was the highly traditional Christmas pudding (formerly known as Plum Pudding). After 1976, too few recipes retained the name pudding for reliable analysis. To understand the reason, we need to look at the category names applied to the different sweetened dishes through time.

As the 20th century approached, the term 'pudding' was applied more widely than ever before. It extended beyond the baked and boiled varieties, to gelled, frozen or iced dishes. However, the revolution in the structure of the English formal dinner placed the dish category names under pressure. Under the old system, referred to as service à la française, there were two main courses with a symmetrical arrangement of dishes. While fish and soup were always part of the first course, and game of the second, a pudding could appear in either, as we have seen from the Woodforde diaries. After the cloth had been removed, dessert (from French desservir) was placed on the table. It consisted of fruit, nuts and sweetmeats, and from the 18th century onwards, increasing numbers of jellies and creams. The adoption of service à la russe in the second half of the 19th century meant that a procession of dishes was brought to the table, raising questions as to the correct classification and position for the various types of puddings. While the hot sweet dishes retained the name pudding in Britain, the various creams and jellies were increasingly classified as 'cold sweets'. In North America, the preferred term was 'desserts'. Through the first half of the 20th century, the English ate hot puddings or cold sweets, while the Americans increasingly used 'desserts' as an umbrella term for all sweet dishes, whether hot or cold. Individual recipes might be called an Indian pudding, for example, but they were to be found in the desserts section of the cookbooks.

In New Zealand, where I have examined the terminology of both hot and cold sweet dishes in 855 New Zealand-published cookbooks (predominantly fundraisers) from 1888 to 1999, dessert sections make their first appearance in the 1930s and 1940s, unquestionably as a result of American influences. At first, the term was more acceptable as the category name for collections of cold sweet dishes, but from the 1970s, half of the recipe books classified hot sweet dishes as desserts, while the remainder clung to the name pudding. By the 1990s, only 15 percent of cookbooks used the category name pudding for hot sweet dishes (see Table 2). Individually, progressively fewer recipes carried the name pudding. A similar replacement of the pudding category name by dessert in England led to an editorial in The Times (February 3 1965), and an exchange of letters in 1971. To one correspondent who insisted that in Britain the course was known as 'the sweet', cookbook writer Robin McDouall replied 'Let him speak for himself: others call it pudding' (The Times, September 6 1971:15).

The collapse of the term 'pudding' for the sweet dishes eaten after the main course has been dramatic and may even lead to a complete loss of the generic term, to the point where no cookbook will have a section entitled 'puddings', though they will probably retain recipes for individual puddings, such as Christmas pudding. Does this mean that puddings will die out? It 
Table 2. Changing category or section names for hot sweet dishes in 855 New Zealand cookbooks, 1888-1999.

\begin{tabular}{lllllllllllll}
\hline Year & $1880 s$ & $1890 s$ & $1900 s$ & $1910 s$ & $1920 s$ & $1930 s$ & $1940 s$ & $1950 s$ & $1960 s$ & $1970 s$ & $1980 s$ & $1990 s$ \\
\hline Sections n=848 & 2 & 1 & 14 & 19 & 35 & 61 & 51 & 81 & 129 & 171 & 189 & 95 \\
Puddings & 2 & 1 & 14 & 19 & 34 & 59 & 44 & 72 & 77 & 82 & 66 & 14 \\
Sweets & 0 & 0 & 0 & 0 & 0 & 0 & 3 & 3 & 6 & 4 & 5 & 7 \\
Desserts & 0 & 0 & 0 & 0 & 1 & 2 & 4 & 6 & 46 & 85 & 118 & 73 \\
Afters & 0 & 0 & 0 & 0 & 0 & 0 & 0 & 0 & 0 & 0 & 0 & 1 \\
\hline
\end{tabular}

is worth remembering that Polynesian puddings never had a generic name, despite existence for two or three millennia. But to survive as an un-named category, the context of production has to be socially significant, which was the case in Polynesia. We cannot say the same of all English puddings. Eventually, consumers of the Christmas pudding may become as ignorant of its origins and history as they are today of the black pudding's. Nowadays, few people eat black pudding and even fewer know why it is called a pudding. It is possible that we will see the virtual extinction of 'pudding' both as category name and as part of an individual recipe's binomial within the next century. The dishes will continue to evolve, but under different names. But to my mind, dishes labelled 'afters' are much less desirable or enriched with historical associations than 'puddings'.

\section{Acknowledgements}

Some of the research for this paper was supported by the Marsden Fund of the Royal Society of New Zealand, and was part of a three-year project on the development of New Zealand's culinary traditions. Thanks are due to members of the research team who provided references and data, and especially to Jane Teal for comments. I must acknowledge To'aiga Su'a whose M.A. thesis (1987) provided the Polynesian foundation. I am also grateful to Peter Gathercole and Fiona Lucraft (UK) who attempted to find an answer to the question 'What is a Norfolk Pudding?' A shortened version of this paper was delivered to the David Nichol Smith Seminar in 18th-Century Studies XIII in Dunedin in April 2007.

\section{References}

Anon [A Lady] 1827. Domestic Economy, and Cookery, for Rich and Poor. London: Longman, Rees, Orme, Brown, and Green.

Anon [c. 1875]. Cassell's Dictionary of Cookery. London: Cassell Petter and Galpin.

Arbuthnot, J. 1751. The Miscellaneous Works of the Late Dr. Arbuthnot, Vol.1, James Carlile, Glasgow, viewed 30 March 2007, on Eighteenth Century Collections Online, <http://galenet.galegroup. $\mathrm{com} / \mathrm{servlet} / \mathrm{ECCO}>$

Austin, T. (ed) 1888. Two Fifteenth-Century Cookery-Books, Oxford: Oxford University Press.

Bailey, N. 1726. An Universal Etymological English Dictionary, 3rd edition. London: J.Darby, viewed 30 March 2007, on Eighteenth Century Collections Online, <http://galenet.galegroup.com/servlet/ $\mathrm{ECCO}>$

Bailey, N. 1728. An Universal Etymological English Dictionary, 4th edition. London: J.Darby, viewed 30 March 2007, on Eighteenth Century Collections Online, <http://galenet.galegroup.com/servlet/ $\mathrm{ECCO}>$ 
Bailey, N. 1737. An Universal Etymological English Dictionary, 8th edition. London : D. Midwinter. Beaglehole, J.C. (ed) 1967. The Voyage of the Resolution and Discovery 1776-1780. London: The Hakluyt Society.

Beecher, C.E. 1850. Miss Beecher's Domestic Receipt Book. New York: Harper, viewed 30 March 2007, <http://digital.lib.msu.edu/projects/cookbooks/html/project.html>

Beeton, I. 1869. The Book of Household Management, 2nd edition. London: Ward, Lock, and Tyler.

Beresford, J. (ed) 1927. The Diary of a Country Parson: the Reverend James Woodforde, Vol. III 1788-1792. London: Oxford University Press.

Beresford, J. (ed) 1929. The Diary of a Country Parson: the Reverend James Woodforde, Vol. IV 1793-1796. London: Oxford University Press.

Beresford, J. (ed) 1931. The Diary of a Country Parson: the Reverend James Woodforde, Vol. V 1797-1802. London: Oxford University Press.

Beresford, J. (ed) 1978. The Diary of a Country Parson 1758-1802 by James Woodforde. Oxford: Oxford University Press.

Carey, H. 1726. A learned Dissertation on Dumpling; its dignity, antiquity, and excellence. With a word upon pudding... 2nd edition. London : J. Roberts, viewed March 30 2007, on Eighteenth Century Collections Online, <http://galenet.galegroup.com/servlet/ECCO>

Chapman, R.W. (ed) 1930. Johnson's Journey to the Western Islands of Scotland; and, Boswell's Journal of a Tour to the Hebrides with Samuel Johnson, LL.D. London: Oxford University Press.

Ellis, W. 1750. The Country Housewifés Family Companion. London: James Hodges, viewed March 30 2007 on Eighteenth Century Collections Online, <http://galenet.galegroup.com/servlet/ECCO>

Fisher, L. 1788. The Prudent Housewife, or, Compleat English Cook... 24th ed., Women Advising Women, Part 6. Wiltshire: Adam Matthew Microfilms.

Forster, G. 2000. A Voyage Round the World, Vol. 1., Nicholas Thomas and Oliver Berghof (eds). Honolulu: University of Hawaii Press,.

Frazer, Mrs. 1791. The Practice of Cookery, Pastry, Pickling, Preserving. Edinburgh: Peter Hill, viewed March 302007 on Eighteenth Century Collections Online, <http:/galenet.galegroup.com/ servlet/ECCO>

Gillette, F.L. 1887. White House Cook Book: a selection of choice recipes... Chicago: R.S. Peale and Co, viewed March 30 2007, <http://digital.lib.msu.edu/projects/cookbooks/html/project.html>

Glasse, H. 1995. The Art of Cookery Made Plain and Easy, facsimile of 1 st edition of 1747. Devon: Prospect Books.

Guthrie W.C.E. 1911. The School Cookery Book. London: Macmillan.

Hess, K. 1981. Martha Washington's Booke of Cookery. New York: Columbia University Press.

Howland, E.A. 1845. The New England Economical Housekeeper, and Family Receipt Book. Cincinatti: H.W. Derby, viewed March 30 2007, <http://digital.lib.msu.edu/projects/cookbooks/html/ project.html>

Johnstone, C.I. [Margaret Dods, pseudonym] 1826. The Cook and Housewife's Manual, Women and Victorian Values, 1837-1910, Part 7. Wiltshire: Adam Matthew Microfilms.

Kelsey, M.W. 1995. The Pudding Club and Traditional British Puddings. In H. Walker (ed), Disappearing Foods. Studies in foods and dishes at risk. Proceedings of the Oxford Symposium on Food and Cookery 1994, pp. 116-123. Devon: Prospect Books.

Kettilby, M. 1714. A Collection of Above Three Hundred Receipts in Cookery, Physick and Surgery, London: Richard Wilkin, viewed March 30 2007, on Eighteenth Century Collections Online, $<$ http://galenet.galegroup.com/servlet/ECCO>

Kirch, P.V.and G. Roger 2001. Hawaiki, Ancestral Polynesia. An essay in historical anthropology. Cambridge: Cambridge University Press.

Kitchiner, W. 1817. Apicius Redivivus; or, The Cook's Oracle, Women Advising Women, Part 6. Wiltshire: Adam Matthew Microfilms. 
Lea, E.E. 1869. Domestic Cookery, Useful Receipts, and Hints to Young Housekeepers. Baltimore: Cushings and Bailey, viewed March 30 2007, <http://digital.lib.msu.edu/projects/cookbooks/ $\mathrm{html} /$ project.html>

Leach, H.M. 1989. The traditional background of Polynesian foods, Proceedings of the Nutrition Society of New Zealand 14:131-136.

Leach, H.M. 2003, Did East Polynesians have a concept of luxury foods?. World Archaeology 34(3):442-457.

Leach, H.M. 2006. From Dunoon to Dunedin - what two distant charitable cookbooks reveal about the British tradition of soups. Petits Propos Culinaires 80:33-59.

Lehmann, G. 1999a. English Cookery Books of the 18th Century. In A. Davidson (ed), The Oxford Companion to Food, pp. 277-279. Oxford: Oxford University Press.

Lehmann, G. 1999b. Politics in the Kitchen. Eighteenth-Century Life 23(2):71-83.

Lepofsky, D.S. 1994. Prehistoric agricultural intensification in the Society Islands, French Polynesia. $\mathrm{PhD}$, University of California, Berkeley, University Microfilms International, Ann Arbor.

Leslie, E. 1840. Directions for Cookery, in its Various Branches. Philadelphia: E.L. Carey and Hart, viewed March 30 2007, <http://digital.lib.msu.edu/projects/cookbooks/html/project.html>

May, R. 2000. The Accomplisht Cook, or the Art and Mystery of Cookery, facsimile of 5th edition of 1685. Devon: Prospect Books.

Miller, H.K. 1956, The Paradoxical Encomium with Special Reference to its Vogue in England, 1600-1800. Modern Philology 53(3):145-178.

Moxon, E. 1769. English Housewifery. Exemplified in above four hundred and fifty receipts... 10th edition. Leeds: Griffith Wright, viewed March 30 2007, on Eighteenth Century Collections Online, <http://galenet.galegroup.com/servlet/ECCO>

Murrell, J. 1615. A New Booke of Cookerie; London Cookerie. London: John Browne, viewed March 30 2007, <http://homepage.univie.ac.at/thomas.gloning/tx/1615murr.htm>

Oxford English Dictionary Online 2006-7. Oxford: Oxford University Press, viewed March 30 2007, $<$ http://dictionary.oed.com/entrance.dtl>

Parkinson, S. 1972. A Journal of a Voyage to the South Seas, in His Majesty's Ship, the Endeavour. Adelaide: Libraries Board of South Australia.

Payne, A.G. (ed) 1916. Cassell's Shilling Cookery. London, Cassell and Company.

Perkins, W.L. 1949. The Boston Cooking-School Cook Book by Fannie Merritt Farmer, 8th edition. London: George G. Harrap and Co.

Raffald, E. 1970. The Experienced English Housekeeper, facsimile of 8th edition of 1782. London: E and W Books.

Rogers, B. 2003. Beef and Liberty. Roast beef, John Bull and the English nation. London: Chatto and Windus.

Smith, E. 1734. The Compleat Housewife, 6th edition, Women Advising Women, Part 6. Wiltshire: Adam Matthew Microfilms.

Su'a, T.I. 1987. Polynesian pudding processes in West and East Polynesia. An ethnographic, linguistic and archaeological synthesis to study the antiquity of elaborate culinary concoctions in Polynesia, MA, University of Otago.

Tegetmeier, W.B. 1876. The Scholars' Handbook of Household Management and Cookery. London: Clay, Sons, and Taylor.

The Times Digital Archive 1785-1985, University of Otago Library, viewed March 302007 , <http://infotrac.galegroup.com/itw/infomark/0/1/1/purl=rc6_TTDA?sw_aep=otago> 